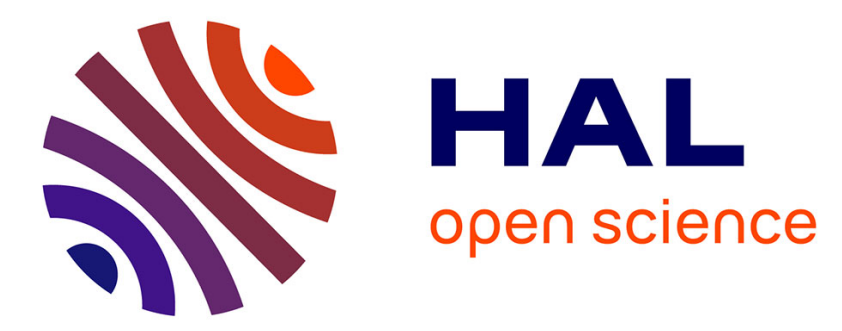

\title{
Estimation of combustion engine technical state by multidimensional analysis using SVD method
}

\author{
Ronald Martinod, German R Betancur, Leonel Castañeda, Tomasz \\ Kalaczyński, Mariusz Żóltowski
}

\section{To cite this version:}

Ronald Martinod, German R Betancur, Leonel Castañeda, Tomasz Kalaczyński, Mariusz Żóltowski. Estimation of combustion engine technical state by multidimensional analysis using SVD method. International Journal of Vehicle Systems Modelling and Testing, 2013, 8 (2), pp.105-118. 10.1504/IJVSMT.2013.054476 . hal-02182276

\section{HAL Id: hal-02182276 \\ https://hal.science/hal-02182276}

Submitted on 12 Jul 2019

HAL is a multi-disciplinary open access archive for the deposit and dissemination of scientific research documents, whether they are published or not. The documents may come from teaching and research institutions in France or abroad, or from public or private research centers.
L'archive ouverte pluridisciplinaire HAL, est destinée au dépôt et à la diffusion de documents scientifiques de niveau recherche, publiés ou non, émanant des établissements d'enseignement et de recherche français ou étrangers, des laboratoires publics ou privés. 


\title{
Estimation of combustion engine technical state by multidimensional analysis using SVD method
}

\author{
Ronald M. Martinod, German R. Betancur and \\ Leonel F. Castañeda
}

Mechanical Engineering Department, Universidad EAFIT,

Cra. 49 N 7 Sur - 50, Medellín, Colombia

E-mail: rmartino@eafit.edu.co

E-mail: gbetanc4@eafit.edu.co

E-mail: lcasta@eafit.edu.co

\section{Tomasz Kałaczyński* and Mariusz Żółtowski}

Wydział Inżynierii Mechanicznej,

University of Technology and Life Sciences in Bydgoszcz,

Ul. S. Kaliskiego 7, 85 - 796, Bydgoszcz, Poland

E-mail: kalaczynskit@mail.utp.edu.pl

E-mail: mariusz.zoltowski@utp.edu.pl

*Corresponding author

\begin{abstract}
The changes of vibration estimators as a result of engine maladjustment, waste, damage or failure are the main idea of vibrodiagnostic investigation. Diagnostic investigations that use vibration to determine the technical state of combustion engines are very difficult. A limited set of proposed methods could have use in diagnostics. This paper presents a validation of research results of the use of the singular value decomposition (SVD) method. The research object is a combustion engine with power $55 \mathrm{~kW}$ at $830 \mathrm{rpm}$, which is feasible to obtain signals generated by vibration, as well as investigate the influence of the engine in the variation of the vibroacoustic data. Using the SVD method is possible to decide which symptom in the observation matrix is the best to recognise the technical state of combustion engines.
\end{abstract}

Keywords: combustion engine; diagnostic inference; damage; symptoms; coherence function; Neyman-Pearson theory; probability density function; PDF; singular value decomposition; SVD; multivariable regression; vibration analysis.

Reference to this paper should be made as follows: Martinod, R.M., Betancur, G.R., Castañeda, L.F., Kałaczyński, T. and Żółtowski, M. (2013) 'Estimation of combustion engine technical state by multidimensional analysis using SVD method', Int. J. Vehicle Systems Modelling and Testing, Vol. 8, No. 2, pp.105-118.

Biographical notes: Ronald M. Martinod obtained his MS from Universidad EAFIT, Colombia. His major research fields are dynamic modelling of railways and the non-linear analysis of vehicles. 
German R. Betancur obtained his BS and MS Engineer from Universidad EAFIT. He is co-investigator in the Research Group of Industrial Maintenance (GEMI), responsible for developing of dynamic tests to engineering systems such as vehicles, wind turbines and hydraulic generators.

Leonel $\mathrm{F}$. Castañeda received his $\mathrm{PhD}$ from the University of Technology and Life Sciences in Bydgoszcz, Poland and his MS from the University of Science and Technology of Krakow, Poland. He is Professor of the Mechanical Engineering Department and Coordinator of the GEMI Research Group, technical diagnosis line. His research interests include topics related to mechanic vibration and technical diagnosis.

Tomasz Kałaczyński obtained his MS from the University of Technology and Agriculture in Bydgoszcz and his PhD from University of Technology and Life Sciences in Bydgoszcz. He is a Professor of the Faculty of Engineering. His research interests include vibration measure and operational modal analysis for the technical state evaluation of combustion engine.

Mariusz Żółtowski obtained his $\mathrm{PhD}$ from the Technical University of Szczecin, Poland. He is an Assistant Professor at the University of Technology Life and Science in Bydgoszcz. His research interests include the study of building material, management and information technologies used in the management, planning, implementation and preparation of results of experiments.

\section{Introduction}

The technical state of engineering systems (civil engineering, mechanical systems, motion mechanical structures such as airplanes, vehicles, boats, and mobile machinery in general) can be described through a set of parameter values that define an object in a given moment of the particular dynamic instant time, $t$ (Martinod et al., 2012; Castañeda et al., 2012). The time sequences of these states could be considered as the time of existence of the system, operating time $\Theta$. The use of technical diagnostic methods makes possible the qualification of engineering systems current technical states (Źółtowski, 2002; Żółtowski and Cempel, 2004).

The main problem is to link the engineering systems in operational conditions to the procedure methods that diagnose the technical state. The present studies and development (technical equipment assembled to software) create new possibilities for diagnosing engineering systems and monitoring technical condition of more folded mechanical constructions (Żółtowski, 2002; Żółtowski and Cempel, 2004).

Diagnostic researches that use vibration to determine the technical state of combustion engines are very difficult to apply on the practical field, and a limited set of proposed methods could have use in diagnostics. This paper aims to put forward an application of SVD method focused on the identification of the technical state of combustion engines. 


\section{Technical state diagnostic based on SVD method}

Given a set of symptoms from vibroacoustics signals which describes the technical state of the engineering system through a symptom matrix observation $S(\Theta)$. SVD method is the appropriate tool for analysing a mapping from one vector space $S\left(\Theta_{k}\right)$ into another vector space, possibly with a different dimensional vectoring (Cempel, 2005a; Kałaczyński and Łukasiewicz, 2007; Kałaczyński and Żółtowski, 2008; Łukasiewicz, 2008); the general procedure of SVD application is shown in Figure 1.

Figure 1 SVD general procedure

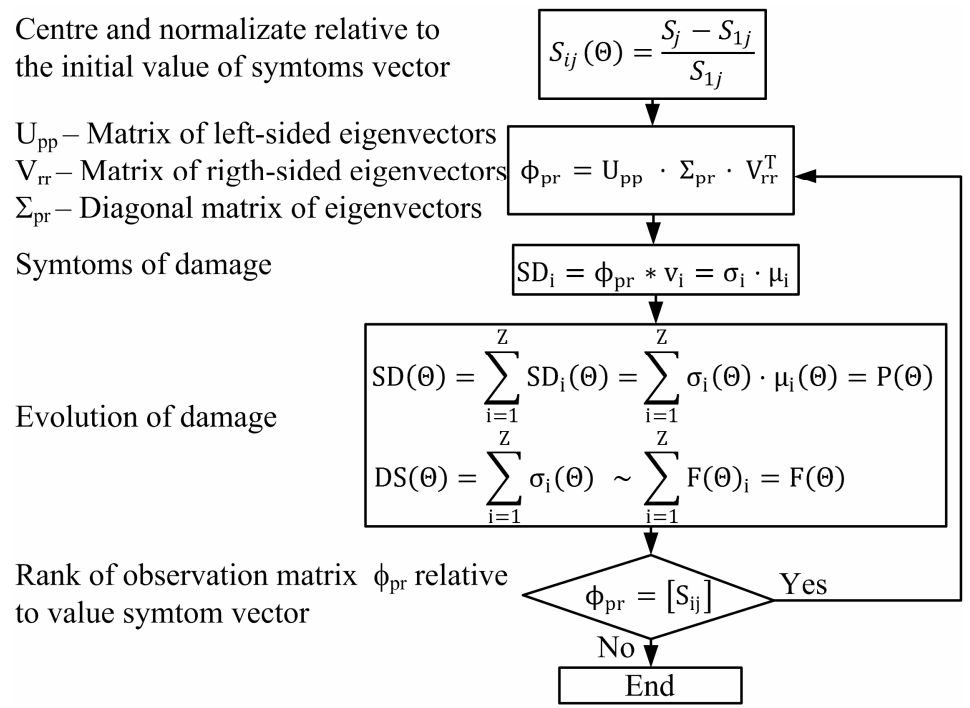

Source: Żółtowski and Cempel (2004), Cempel (2005b) and Żółtowski et al. (2008)

The main diagonal of the matrix $\Sigma_{p r}$, becomes the eigenvalues $\Lambda$, it has a physical interpretation, $\Lambda=\left[\mu_{1}, \ldots, \mu_{i}, \ldots, \mu_{k}\right]$ represents the fraction of damage (contribution of fault) in the engineering systems, the set of $\mu_{i}$ has a limited value attached $\lambda_{\lim }$, and it represents failure of the first failure status $\mu_{1}$.

By using the SVD method it is possible to determine $S D_{i}$ the index, which is defined as the discriminant of the failure $i^{\text {th }}$ (Cempel et al., 2003). $S D_{i}$ is a sensible symptom to a specific failure and therefore each $S D_{i}$ is used for distinguishing between various failures that evolve in the system. $S D_{i}$ contains independent information about the failure mode and also on the intensity of this failure for the inclusion of $\sigma_{i}(\mathrm{Cempel}, 2005 \mathrm{a})$

$$
S D_{i}=\phi_{p r} \cdot v_{i}=\sigma_{i} \cdot \mu_{i} .
$$

An advance of the failure $F_{i}\left(\theta_{k}\right)$ in the operation time $\theta_{k}$ can be described through the $S D_{i}\left(\theta_{k}\right)$ discriminant. Therefore, it is possible to affirm that (Cempel et al., 2003)

$$
S D_{i}\left(\Theta_{k}\right) \sim F_{i}\left(\Theta_{k}\right) .
$$


A similar inference can be postulated for the significance and evolution of the sum of the quantities, obtaining the total profile of the damage $\operatorname{Sum} S D(\theta)$ expressed in the following form (Ganzo, 2003).

$$
\operatorname{SumSB}(\Theta)=\sum_{i=1}^{z}\left|S D_{i}(\Theta)\right|=\sum_{i=1}^{z}\left|\sigma_{i}(\Theta) \cdot \mu_{i}(\Theta)\right| \sim \sum_{i=1}^{z}\left|F_{i}(\Theta)\right| .
$$

If any single value were to be zero, then the corresponding factor does not provide variability, does not provide inertia to the total inertia of the dataset, and does not explain any part of the total inertia. This allows presiding from such factor, meaning that each factor collaborates to the total inertia in a quantity equal to (Ganzo, 2003).

Then, the results obtained from the SVD are introduced with concepts of decision theory to establish the state of the failure condition. Two hypotheses in which the symptom will be classified are considered (Natke and Cempel, 1997): good condition $w_{G}$, and failure condition $w_{F}$. The posteriori probability of each type is $p\left(w_{i} \mid S\right)$, the decision rule using Bayes theory is defined as (Natke and Cempel, 1997) $w_{G}$ if and only if

$$
\frac{p\left(S \mid w_{G}\right)}{p(S)}>\frac{p\left(S \mid w_{F}\right)}{p(S)},
$$

otherwise is $w_{G}$, where $p\left(S \mid w_{G}\right)$ is the probability density function (PDF) in respect to a good symptom condition $S$, and $p\left(S \mid w_{F}\right)$ is the PDF of failure state of the symptom $S$.

The pondering of the posteriori conditional PDF is done with the a priori probability $p\left(w_{i}\right)$. Consequently, the decision rule can be formulated as the probability ratio (Natke and Cempel, 1997) $w_{G}$ in the case that

$$
l(S)=\frac{p\left(S \mid w_{G}\right)}{p\left(S \mid w_{F}\right)}>\frac{p\left(w_{G}\right)}{p\left(w_{F}\right)},
$$

and $w_{F}$ in the opposite case. Generally, the frontier of decision is defined through the equality of the pondered conditional PDFs $p\left(S \mid w_{G}\right) p\left(w_{G}\right)=p\left(S \mid w_{F}\right) p\left(w_{F}\right)$ (Natke and Cempel, 1997).

One of the types of fixed error probability is the rule of Neyman-Person, which is treated in this study. Neyman-Pearson allows committing the error of wrongly classifying a good condition as the beginning of a failure over a probability level of $A$ (Natke and Cempel, 1997)

$$
A=G \int_{S_{l}}^{+\infty} p\left(S \mid w_{G}\right) d S=G R\left(S_{l}\right)
$$

where $A$ is the probability of unnecessary reparations and is the reliability of the system under service. It must be recalled that the preceding integral is nothing else but the reliability of the previously defined symptom $R(S)=\int_{S} p\left(S \mid w_{G}\right) d S$ (Natke and Cempel, 1997). In diagnostic the probability of a wrong classification for a good condition is usually fixed to a low level $(A=0.05)$.

The final stage of analysis is the correlation symptoms procedure with the selected failure. The analysis of correlation symptoms with the selected failure allows ranking the symptoms due to the correlation coefficient value. 


\section{Model of diagnostics signal generation}

The research engineering system has been a combustion engine (No. 138C.2.048) with 1.4 l. swept capacity, power $55 \mathrm{~kW}$ at $830 \mathrm{rpm}$, commonly assembled to fiat vehicles. It is possible to introduce generated vibration signals as well as the research of its adjustment influence on the combustion engine vibration signals change (Kałaczyński and Łukasiewicz, 2007; Kałaczyński and Żółtowski, 2008; Łukasiewicz, 2008). The combustion engine has been situated under controlled conditions in the investigative laboratory of combustion engines in Bydgoszcz (Figure 2). Figure 3 shows the failure of the spark plug electrodes modelled by removing the side electrode and the injector damage modelled by releasing the signal cable.

Figure 2 Measuring chain flow-graph

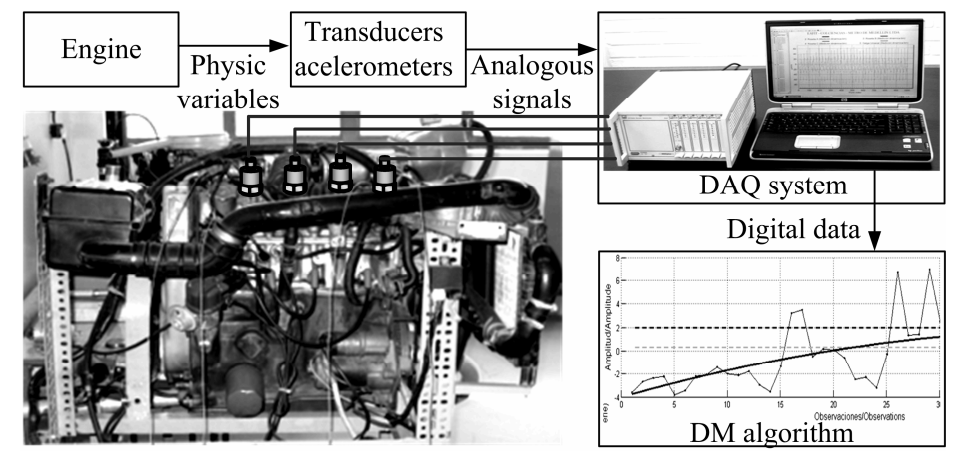

Figure 3 Failure of removing the spark plug side electrode

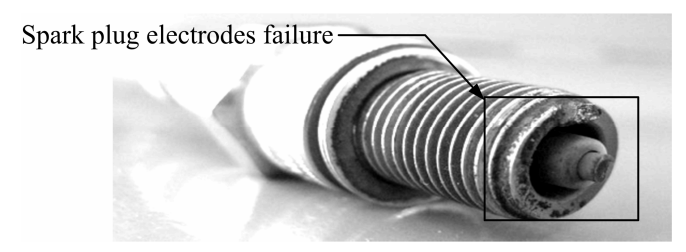

A set of tests has been developed using the object of research in the laboratory, a total of 33 technical states were simulated with damages of spark plug and injectors on the individual cylinders of the engine and the combination of these damages. Based on the performance of the engine, a model of diagnostic signal generation was created during the investigations (Figure 4) (Żółtowski, 2002; Kałaczyński and Łukasiewicz, 2007; Kałaczyński and Żółtowski, 2008; Łukasiewicz, 2008).

During the experimental research, uniform conditions in the engine were needed in order to guarantee the success of the analytical process. The research was performed under the following conditions:

- for neutral gear - temperature of the trunk of the engine carried out $71^{\circ} \mathrm{C}$

- the investigations were executed using two measuring channels for the fulfilment of the state of Fourier transformation, acceleration sensors ICP 352C68 model

- two leads series 002 . 
The excitation inputs in any point of the engine body are the sum of the answers to all elementary events $u_{i}(t, \Theta)$, the outputs in individual partial dynamic arrangements relative to the pulse input function $h_{i}(t, \Theta)$. After passing by proper dynamic arrangements these influences are summed up on the engine body, then measure points are selected to put vibration transducers. As a result, the output signals of the conducted measurements were used to calculate estimation data. By means of $n(t, \Theta)$ is estimate the accidental influence from presence of dynamic micro effects (such as friction, transfer heat, etc.) (Żółtowski, 2002; Żółtowski and Cempel, 2004; Kałaczyński and Łukasiewicz, 2007; Łukasiewicz, 2008).

Based on computer languages, the diagnostics algorithm called multivariable diagnostic (DM) was develop for vibroacoustics signal analysis, processing and analysing the dataset. A model of the machine in good state and another model of the machine after certain period of usage give an inference base about the state of the object and vibration predominant sources. SVD procedure was included in DM application as a computational module (see Figure 5).

The analysis in DM-SVD algorithm allowed generating eight own measures and eight mutual measures. These measures were analysed by using the SVD method for assessing the diagnostic usefulness of the generated own and mutual measures.

Figure 4 Combustion engine diagnostics signal generation model

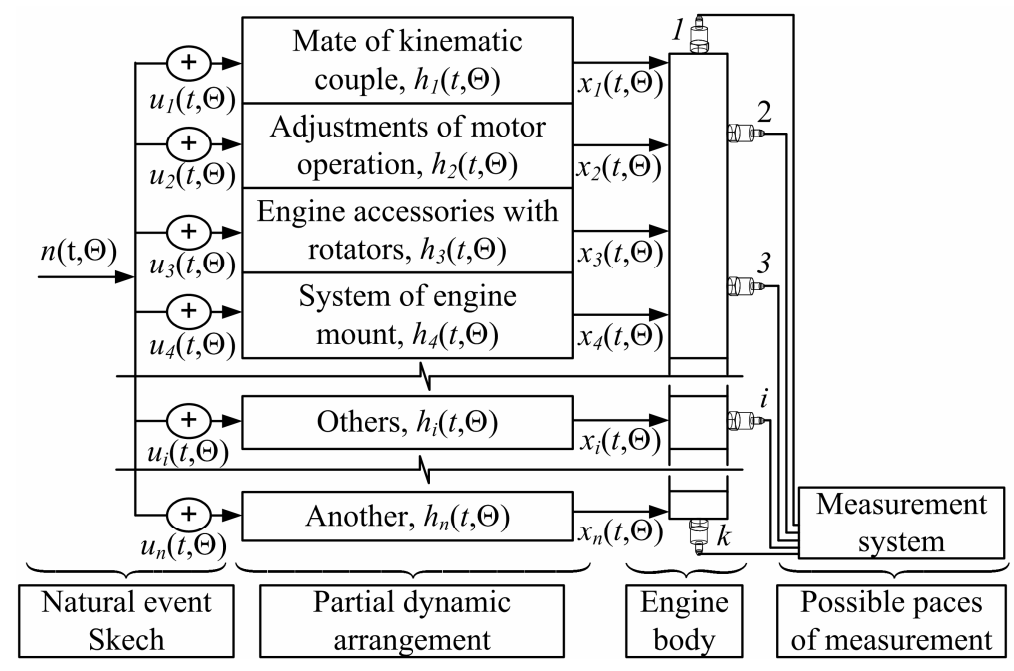

Source: $\quad$ Lukasiewicz (2008)

Figure 5 Main window of the SVD module used for analysis

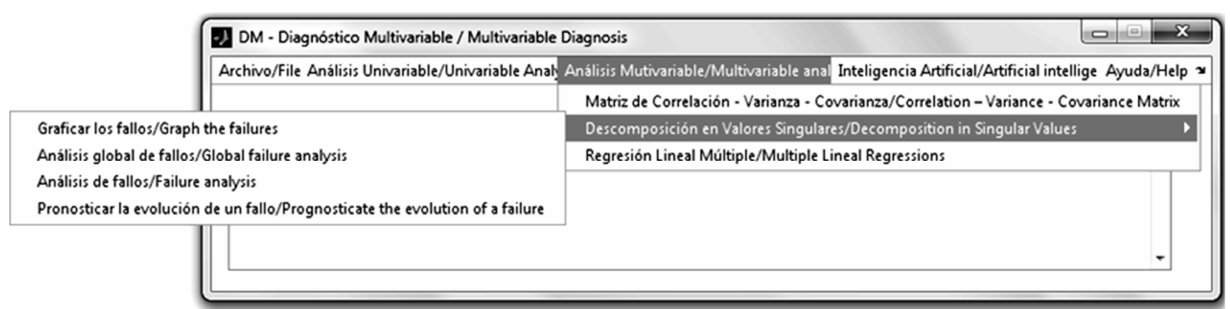




\section{Results of validation}

The present research on combustion engines depended on the delimitation of vibroacoustics signals measured in the engine and comparing them with signals established for damaged engines (e.g., damaged spark plug, injector) to realise the evaluation through operational vibroacoustic methods.

The observation matrices have eight own symptoms ( $x_{\text {ave }}$ - average, $A_{R M S}$ - root mean square, $P_{\max }-$ maximum pick, $\sigma_{j}$ - standard deviation, $K$ - shape factor, $C$ - crest factor, $I$ - impulse factor, $R_{x x}$ - autocorrelation coefficient) and have eight mutual symptoms $\left[\gamma\left(f_{1}\right)\right.$ - coherence value for a first characteristic frequency $12.63 \mathrm{~Hz}, \gamma\left(f_{2}\right)$ - coherence value for a second characteristic frequency $23.27 \mathrm{~Hz}, \gamma\left(f_{3}\right)$ - coherence value for a third characteristic frequency $46.96 \mathrm{~Hz}, \gamma(\Delta f)$ - under area value of the coherence function for the range from the first to the third characteristic frequency, $R_{x y}(\Delta f)$ - under area value of the cross-correlation function for the range from the first to the third characteristic frequency, $\operatorname{FFT}_{x}(\Delta f)$ - under area value of signal spectrum from the first point between the first and the third characteristic frequencies, $F_{F T}(\Delta f)$ - under area value of signal spectrum from the second point between the first and the third characteristic frequencies, $H_{x y}(\Delta f)$ - under area value of the transmittance function for the range from the first to the third characteristic frequencies] (Kałaczyński and Łukasiewicz, 2007; Kałaczyński and Żółtowski, 2008).

The final observation matrices of engine performance are shown in Appendix B, Table 2 describes eight own symptom and Table 3 describes eight mutual symptoms.

For analytical purposes the technical states were classified into three groups:

- $\quad$ first group - damage to the spark plug

- $\quad$ second group - damage to the injector

- third group - damage to the injector and spark plug.

The following figures show the graphical interpretation of own symptoms revealed through the analysis research results with the SVD method:

Percentage of damage (contribution of fault in the engine) in the object status description obtained in DM software is shown in Figure 6 and Figure 7, the line marks a value of $\lambda_{\text {lim }}=50 \%$ failure of the fist failure status $\mu_{1}$. Figure 8 and Figure 9 show the correlation between of individual symptoms and damage root.

The result of the analysis with SVD method obtained five own and five mutual symptoms that best describe the states of the internal combustion engine. The summary of selected symptoms is presented in Table 1.

Figure 6 SVD of the own symptoms of fault in engine, $S D_{i}(\theta)$

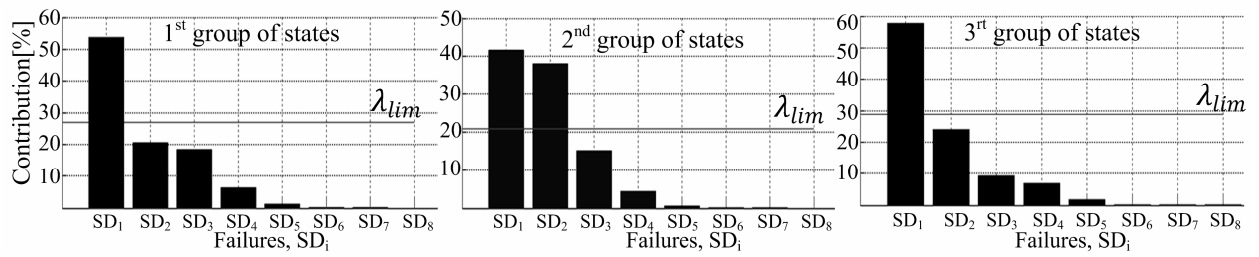


Figure 7 SVD of the mutual symptoms of fault in engine, $S D_{i}(\theta)$

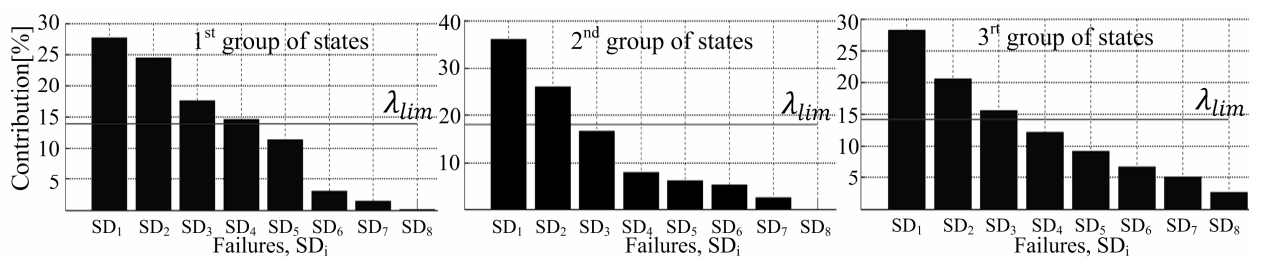

Figure 8 Correlation of own symptoms with the main failure, $S D_{1}(\theta)$

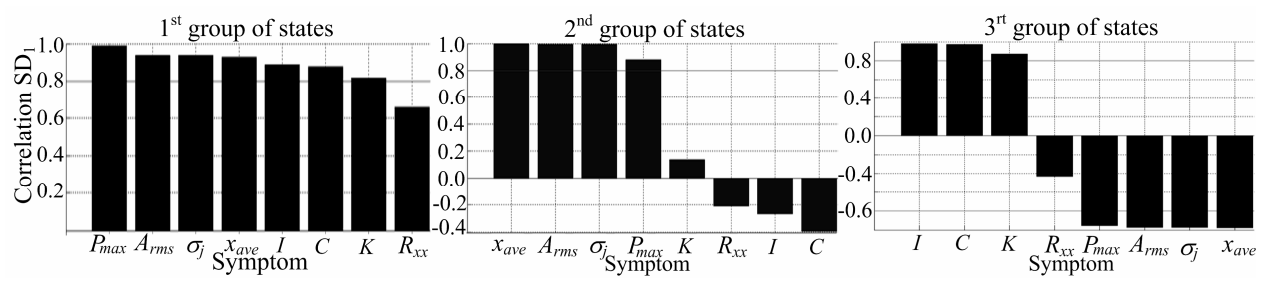

Figure 9 Correlation of mutual symptoms with the main failure, $S D_{1}(\theta)$

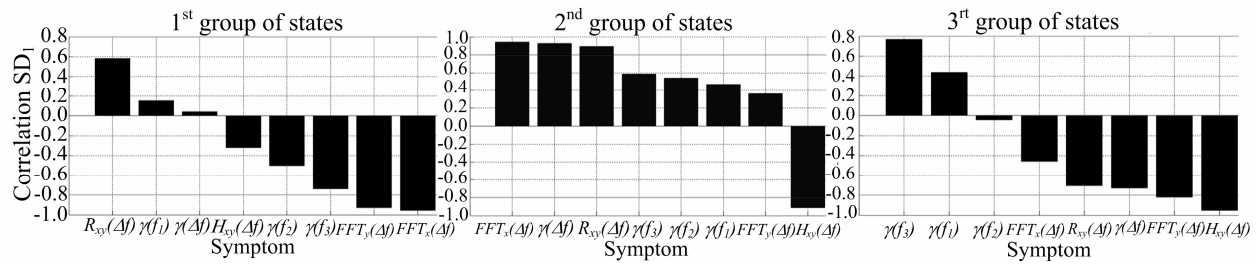

Table 1 Results of SVD method with five own and mutual symptoms that best describe the states of the internal combustion engine

\begin{tabular}{lccccc}
\hline Group state & \multicolumn{5}{c}{ Own symptoms } \\
\hline First group & $P_{\max }$ & \multicolumn{2}{c}{$A_{R M S}$} & $\sigma_{j}$ & $x_{\text {ave }}$ \\
Second group & $x_{\text {ave }}$ & $A_{R M S}$ & $\sigma_{j}$ & $P_{\max }$ \\
Third group & $I$ & \multicolumn{2}{c}{$C$} & $K$ & $A_{R M S}$ \\
\hline \multicolumn{7}{c}{ Mutual symptoms } \\
\hline First group & $R_{x y}(\Delta f)$ & $\gamma\left(f_{1}\right)$ & $\gamma(\Delta f)$ & $F F T_{x}(\Delta f)$ & $\gamma\left(f_{2}\right)$ \\
Second group & $F F T_{x}(\Delta f)$ & $\gamma(\Delta f)$ & $R_{x y}(\Delta f)$ & $\gamma\left(f_{3}\right)$ & $\gamma\left(f_{2}\right)$ \\
Third group & $\gamma\left(f_{3}\right)$ & $\gamma\left(f_{1}\right)$ & $\gamma\left(f_{2}\right)$ & $F F T_{x}(\Delta f)$ & $R_{x y}(\Delta f)$ \\
\hline
\end{tabular}

The analysis indicates the need to assess the technical state using mutual symptoms. The SVD method indicated that mutual symptoms have greater stability to describe the technical state of the engine. Own symptoms play an advisory role, based on which it is not possible to make a clear description of mutual symptoms.

Figure 10 and Figure 11 show a graphic interpretation of the generalised object state $\operatorname{Sum} S D(\theta)$ with Neyman-Pearson analysis, from permissible value for the selected fault, it means $p\left(\operatorname{Sum} S D(\theta) / w_{G}\right)$. 
Figure 10 Histogram of own symptoms with the main failure, $\operatorname{SumSD}(\theta)$

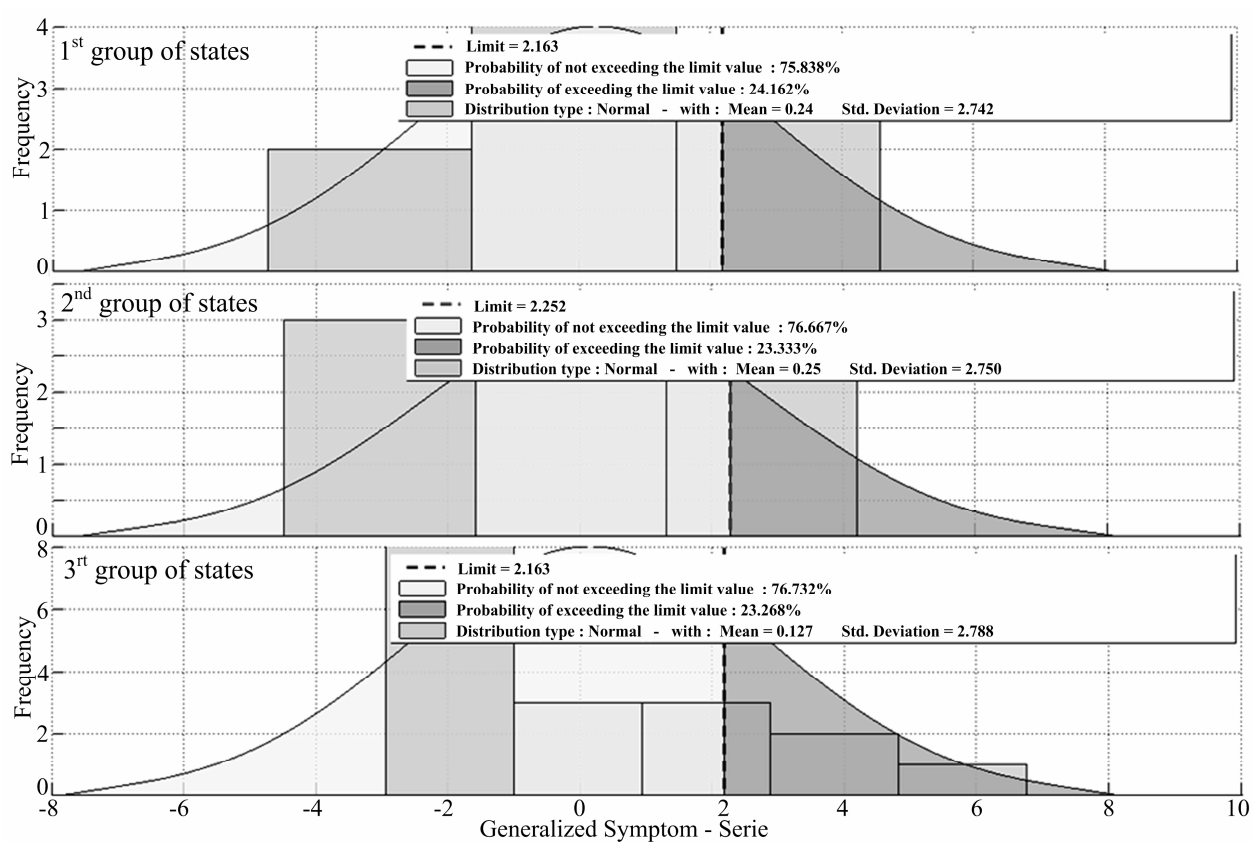

Figure 11 Histogram of mutual symptoms with the main failure, $\operatorname{Sum} S D(\theta)$

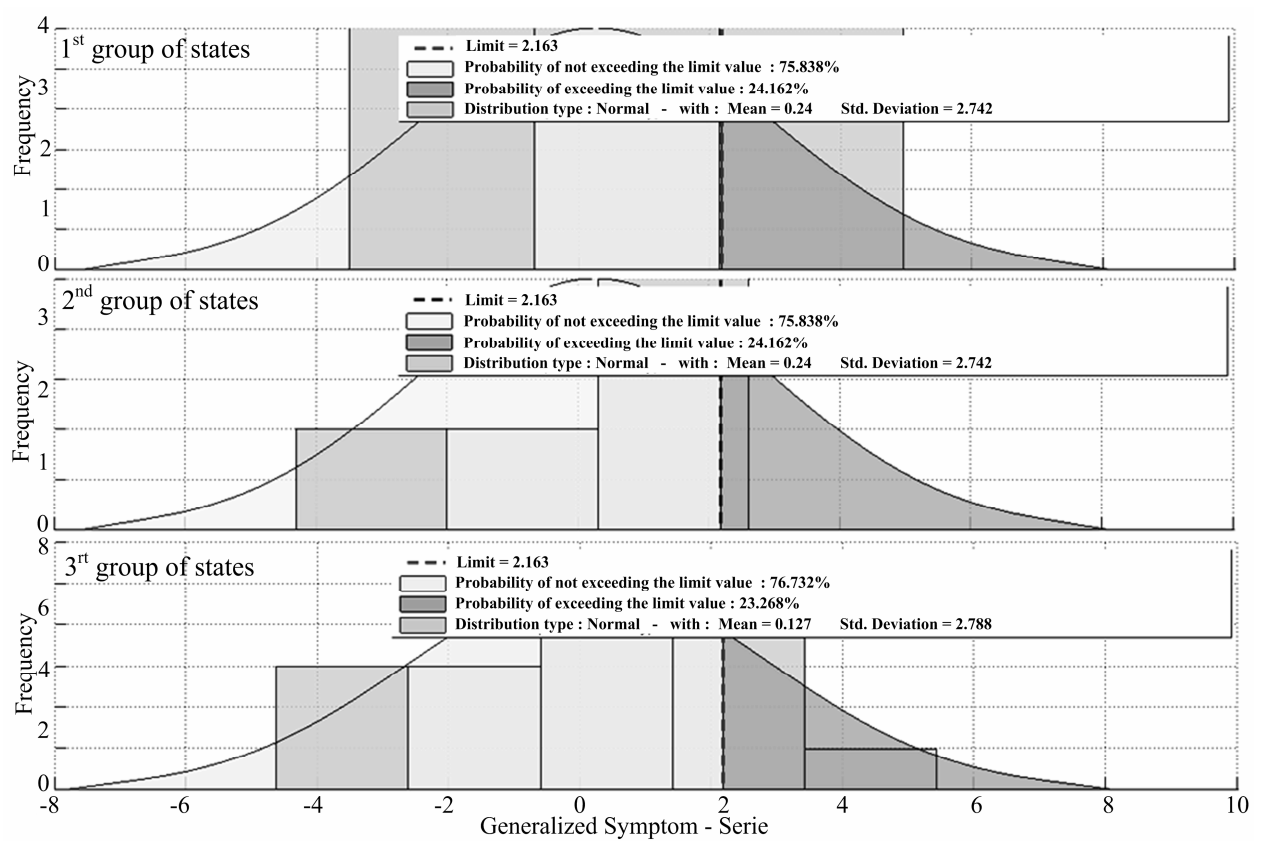

The original solution presented in the article is to use the Neyman-Pearson analysis based on the results of SumSD obtained in the SVD method to assess the quality of the 
conducted test. Neyman-Pearson analysis allowed to generate the parameters describing all groups of states shown in Table 2.

Table 2 Neyman-Pearson results with the main failure, $\operatorname{Sum} \operatorname{SD}(\theta)$

\begin{tabular}{lcccc}
\hline Group state & Mean & Std. deviation & Limit value & Prob. of not exceeding the limit value \\
\hline \multicolumn{5}{c}{ Own symptoms } \\
\hline First group & 0.24 & 2.74 & 2.163 & $75.83 \%$ \\
Second group & 0.25 & 2.75 & 2.252 & $76.67 \%$ \\
Third group & 0.13 & 2.79 & 2.163 & $76.73 \%$ \\
\hline \multicolumn{5}{c}{ Mutual symptoms } \\
\hline First group & 0.24 & 2.742 & 2.163 & $75.84 \%$ \\
Second group & 0.24 & 2.742 & 2.163 & $75.84 \%$ \\
Third group & 0.13 & 2.788 & 2.163 & $76.73 \%$ \\
\hline
\end{tabular}

Values of mean, standard deviation and limit obtained for all groups of states (first, second and third groups) are close, this means that the obtained results in the analysis Neyman-Pearson show correct the tests. Additional information obtained includes probability distributions of $\operatorname{Sum} \operatorname{SD}(\theta)$, these distributions for all groups of states are the normal distributions which confirms correct selection of test conditions for the experiment.

Neyman-Pearson analysis is a good tool to assessment performed experiments. The resulting probabilities of exceeding the limit values of parameters allow the assessment of the nature of the damage affecting the work of the machine. The probability of not exceeding the limit (75\%) should be classified as a failure affecting the values of parameters without affecting the structure of the machine.

\section{Conclusions}

With modern engineering systems, taking into account technological progress and the great opportunities available for acquisition and signal processing, it is possible to obtain a lot of information from the signals recorded in different parts of the machine. This information must be processed and interpreted in most cases by staff to determine the state of the machine.

In the practice of diagnostic investigations, the utilisation of vibrations allows describing the dynamic condition of the machine by a set of estimators from various vibration symptoms.

Received symptoms in the vibroacoustics signal experiment unambiguously show the different technical states of the combustion engine.

The diagnosis of complex systems based on a multidimensional analysis gives the opportunity to evaluate the relationship between symptoms whose values have changed as a result of damage.

SVD method marked the most important symptoms for describing the technical state of engines, the best symptoms are: $\gamma\left(f_{1}\right), \gamma\left(f_{2}\right), \gamma\left(f_{3}\right), \gamma(\Delta f)$.

Among the possible techniques that use the relationship between symptoms is the SVD method. 
SVD method can be used to eliminate symptoms that do not provide important information about the state of the machine that is being tested.

The Neyman-Pearson analysis applied to the main fault has the probability of not exceeding the limit value, which allows the assessment of importance of damage. The obtained value $(75 \%)$ ensures that the propagation of damage has no significant effect on the structure but only on the internal combustion engine operating parameters.

This method allows generating a new set of independent symptoms that may be useful for the diagnosis of technical systems. This is the reason which SVD method is useful in many applications, such as statistics, control theory, and compression, processing a lot of information and evaluating of technical state of complex objects.

The next step of the quantitative and qualitative analysis description of participation symptoms in the assessment of technical state is modelling engine cause-effect relationships using multiple regression (Źółtowski et al., 2008). Modelling makes it possible to identify the relationship between symptoms. SVD method allows the selection symptoms for modelling because it has multidimensionality.

\section{Acknowledgements}

This paper is a part of investigative project WND-POIG.01.03.01-00-212/09.

\section{References}

Castañeda, L.F., Martinod, R.M. and Betancur, G.R. (2012) 'Determination of the technical state of suspension elements based on the OMA-LSCE method', Ingegneria Ferroviaria, January, Vol. 32, No. 1, pp.41-54.

Cempel, C. (2005a) 'Multidimensional condition monitoring of machines in nonstationary operation', ICSV12 Proceedings of International Congress on Sound and Vibration, No. 496, Lisbon.

Cempel, C. (2005b) 'SVD decomposition of symptom observation matrix as the help in a quality assessment of a group of applications', Diagnostyka, Vol. 35, No. 1, pp.7-12.

Cempel, C., Tabaszewski, M. and Krakowiak, M. (2003) 'Extraction methods of multi-fault information in machine condition monitoring', Key Engineering Materials, Vols. 245-246, No. 1, pp.215-222.

Ganzo, A. (2003) Análisis de Datos Multivariantes: Introducción al Análisis Multivariante, Universitat de Les Illes Balears UIB, Departament de Ciències Matemàtiques i Informàtica. España.

Kałaczyński, T. and Łukasiewicz, M. (2007) 'Technical state evaluation of combustion engine using diagnostic properties of the coherence function', Materialy Seminarium Twórczość Inżynierska dla Wspótczesnej Europy, Bydgoszcz, Poland.

Kałaczyński, T. and Żółtowski B. (2008) 'Properties of the coherence function in technical state evaluation of combustion engine', 12th International Conference on Developments in Machinery Design and Control, Nowogród, Poland.

Łukasiewicz, M. (2008) 'Investigation of the operational modal analysis applicability in combustion engine diagnostics', J. of Polisch CIMAC, Vol. 3, No. 2, pp.127-134, Gdańsk, Poland.

Martinod, R.M., Betancur, G.R. and Castañeda, L.F. (2012) 'Identification of the technical state of suspension elements in railway systems', Int. J. Vehicle System Dynamics, Vol. 50, No. 7, pp.1121-1135. 
Natke, H. and Cempel, C. (1997) Model - Aided Diagnosis of Mechanical Systems Fundamentals, Detection, Localization and Assessment, Springer, Berlin.

Żółtowski, B. (2002) Badania Dynamiki Maszyn, ATR, Bydgoszcz, Poland.

Żółtowski, B. and Cempel, C. (2004) Inżynieria diagnostyki maszyn, Polskie Towarzystwo Diagnostyki Technicznej, Warszawa, Poland.

Żółtowski, B., Tylicki, H., Kałaczyński, T. and Castañeda, L. (2008) 'Identification in vibration diagnostics of critical machines', in Zółtowski, B. (Ed.): Knowledge Acquisition for Hybrid Systems of Risk Assessment and Critical Machinery Diagnosis, pp.401-493, Politechnika Śląska, Gliwice.

\section{Appendix A}

Nomenclature

\begin{tabular}{ll}
\hline & Abbreviations, acronyms, coefficients and constants \\
\hline PDF & Probability density function \\
SVD & Singular value decomposition \\
$A_{R M S}$ & Probability of unnecessary reparations \\
$C$ & Root mean square \\
$F F T_{x}(\Delta f)$ & Crest factor \\
$F_{i}\left(\Theta_{k}\right)$ & Under area value of signal spectrum. \\
$G$ & $k^{\text {th }}$ advance of the failure \\
$H_{x y}(\Delta f)$ & Reliability of the system under service \\
$I$ & Under area value of the transmittance function \\
$K$ & Impulse factor \\
$P_{\max }$ & Shape factor \\
$p\left(S \mid w_{F}\right), p\left(S \mid w_{G}\right)$ & Maximum pick \\
$R_{x x}$ & PDF of a failure state of the symptom $S$, and good state, respectively \\
$R_{x y}(\Delta f)$ & Autocorrelation coefficient \\
$S(\Theta)$ & Under area value of the cross-correlation function \\
$S D_{i}$ & Symptom matrix observation \\
$S u m S D(\theta)$ & $i^{\text {th }}$ discriminant of the failure \\
$t$ & Total profile of the damage \\
$x_{a v e}$ & Dynamic instant time \\
$w_{G}, w_{F}$ & Average \\
$\Theta_{k}$ & Good condition, and failure condition, respectively \\
$\gamma\left(f_{i}\right)$ & $k^{\text {th }}$ operating time \\
$\gamma(\Delta f)$ & Coherence value for a $i^{\text {th }}$ characteristic frequency \\
$\mu_{i}$ & Under area value of the coherence function \\
$\sigma_{i}$ & $i^{\text {th }}$ eigenvalue \\
$\sigma_{j}$ & $i^{\text {th }}$ eigenvector \\
\hline & Standard deviation \\
&
\end{tabular}




\section{Appendix B}

\section{Final observation matrix}

Table 3 The final observation matrix for own symptoms

\begin{tabular}{|c|c|c|c|c|c|c|c|c|c|c|c|c|c|c|c|}
\hline \multicolumn{8}{|c|}{ Cylinder damaged } & \multirow{3}{*}{$x_{\text {ave }}$} & \multirow{3}{*}{$A_{R M S}$} & \multirow{3}{*}{$P_{\max }$} & \multirow{3}{*}{$\sigma_{j}$} & \multirow{3}{*}{$K$} & \multirow{3}{*}{$C$} & \multirow{3}{*}{ I } & \multirow{3}{*}{$R_{x x}$} \\
\hline \multicolumn{4}{|c|}{ Sparkplug } & \multicolumn{4}{|c|}{ Injector } & & & & & & & & \\
\hline 1 & 2 & 3 & 4 & 1 & 2 & 3 & 4 & & & & & & & & \\
\hline \multirow[t]{4}{*}{$\mathrm{X}$} & & & & & & & & 0.048 & 0.057 & 0.144 & 0.057 & 1.197 & 2.501 & 2.994 & 0.043 \\
\hline & $\mathrm{X}$ & & & & & & & 0.052 & 0.060 & 0.152 & 0.060 & 1.155 & 2.535 & 2.927 & 0.045 \\
\hline & & $\mathrm{X}$ & & & & & & 0.060 & 0.073 & 0.200 & 0.073 & 1.215 & 2.733 & 3.321 & 0.045 \\
\hline & & & $\mathrm{X}$ & & & & & 0.013 & 0.014 & 0.028 & 0.014 & 1.131 & 1.971 & 2.229 & 0.043 \\
\hline $\mathrm{X}$ & $X$ & & & & & & & 0.054 & 0.065 & 0.191 & 0.065 & 1.213 & 2.936 & 3.561 & 0.047 \\
\hline \multirow[t]{14}{*}{$\mathrm{X}$} & & & $X$ & & & & & 0.076 & 0.090 & 0.218 & 0.090 & 1.195 & 2.412 & 2.882 & 0.045 \\
\hline & $\mathrm{X}$ & $\mathrm{X}$ & & & & & & 0.052 & 0.063 & 0.166 & 0.063 & 1.216 & 2.649 & 3.223 & 0.043 \\
\hline & & $\mathrm{X}$ & $\mathrm{X}$ & & & & & 0.038 & 0.046 & 0.107 & 0.046 & 1.193 & 2.342 & 2.794 & 0.043 \\
\hline & & & & $\mathrm{X}$ & & & & 0.046 & 0.056 & 0.151 & 0.056 & 1.206 & 2.698 & 3.253 & 0.047 \\
\hline & & & & & $X$ & & & 0.304 & 0.365 & 0.815 & 0.365 & 1.201 & 2.235 & 2.684 & 0.050 \\
\hline & & & & & & $X$ & & 0.278 & 0.353 & 0.871 & 0.353 & 1.270 & 2.469 & 3.137 & 0.045 \\
\hline & & & & & & & $X$ & 0.279 & 0.354 & 0.912 & 0.354 & 1.271 & 2.575 & 3.272 & 0.047 \\
\hline & & & & $X$ & $X$ & & & 0.353 & 0.447 & 1.149 & 0.447 & 1.267 & 2.572 & 3.259 & 0.050 \\
\hline & & & & $X$ & & & $X$ & 0.354 & 0.424 & 0.961 & 0.424 & 1.198 & 2.269 & 2.719 & 0.045 \\
\hline & & & & & $\mathrm{X}$ & $X$ & & 0.193 & 0.234 & 0.625 & 0.235 & 1.213 & 2.665 & 3.233 & 0.053 \\
\hline & & & & & & $X$ & $\mathrm{X}$ & 0.235 & 0.317 & 1.081 & 0.318 & 1.352 & 3.405 & 4.605 & 0.055 \\
\hline & $X$ & & & $X$ & & & & 0.355 & 0.411 & 0.868 & 0.411 & 1.160 & 2.111 & 2.449 & 0.045 \\
\hline & & $X$ & & $X$ & & & & 0.352 & 0.403 & 0.833 & 0.403 & 1.146 & 2.069 & 2.371 & 0.047 \\
\hline & & & $\mathrm{X}$ & $X$ & & & & 0.376 & 0.432 & 0.829 & 0.433 & 1.149 & 1.916 & 2.201 & 0.045 \\
\hline \multirow[t]{3}{*}{$X$} & & & & & $X$ & & & 0.273 & 0.319 & 0.700 & 0.319 & 1.169 & 2.193 & 2.563 & 0.040 \\
\hline & & $X$ & & & $X$ & & & 0.188 & 0.215 & 0.619 & 0.216 & 1.144 & 2.874 & 3.286 & 0.050 \\
\hline & & & $X$ & & $X$ & & & 0.272 & 0.311 & 0.718 & 0.311 & 1.142 & 2.311 & 2.639 & 0.050 \\
\hline \multirow[t]{3}{*}{$X$} & & & & & & $X$ & & 0.103 & 0.133 & 0.431 & 0.133 & 1.292 & 3.234 & 4.177 & 0.018 \\
\hline & $X$ & & & & & $X$ & & 0.347 & 0.398 & 0.889 & 0.399 & 1.146 & 2.231 & 2.558 & 0.047 \\
\hline & & & $X$ & & & $X$ & & 0.188 & 0.214 & 0.539 & 0.214 & 1.136 & 2.518 & 2.861 & 0.053 \\
\hline \multirow[t]{3}{*}{$X$} & & & & & & & $X$ & 0.348 & 0.400 & 0.827 & 0.400 & 1.147 & 2.069 & 2.373 & 0.045 \\
\hline & $X$ & & & & & & $X$ & 0.359 & 0.413 & 0.868 & 0.413 & 1.152 & 2.101 & 2.420 & 0.045 \\
\hline & & $X$ & & & & & $X$ & 0.223 & 0.252 & 0.551 & 0.252 & 1.131 & 2.190 & 2.477 & 0.050 \\
\hline \multirow[t]{4}{*}{$X$} & & & & $X$ & & & & 0.361 & 0.412 & 0.851 & 0.412 & 1.141 & 2.067 & 2.357 & 0.047 \\
\hline & $X$ & & & & $X$ & & & 0.152 & 0.182 & 0.509 & 0.182 & 1.197 & 2.799 & 3.351 & 0.047 \\
\hline & & $X$ & & & & $X$ & & 0.082 & 0.102 & 0.300 & 0.102 & 1.232 & 2.955 & 3.639 & 0.045 \\
\hline & & & $X$ & & & & $\mathrm{X}$ & 0.050 & 0.064 & 0.220 & 0.064 & 1.275 & 3.448 & 4.394 & 0.045 \\
\hline
\end{tabular}


Table 4 The final observation matrix for mutual symptoms

\begin{tabular}{|c|c|c|c|c|c|c|c|c|c|c|c|c|}
\hline \multicolumn{5}{|c|}{ Cylinder damaged } & \multirow{3}{*}{$\gamma\left(f_{1}\right)$} & \multirow{3}{*}{$\gamma\left(f_{2}\right)$} & \multirow{3}{*}{$\gamma\left(f_{3}\right)$} & \multirow{3}{*}{$\gamma(\Delta f)$} & \multirow{3}{*}{$R_{x y}(\Delta f)$} & \multirow{3}{*}{$F F T_{x}(\Delta f)$} & \multirow{3}{*}{$F F T_{y}(\Delta f)$} & \multirow{3}{*}{$H_{x y}(\Delta f)$} \\
\hline \multicolumn{3}{|c|}{ Spark plug } & \multicolumn{2}{|c|}{ Injector } & & & & & & & & \\
\hline 1 & 23 & 34 & 12 & 34 & & & & & & & & \\
\hline \multirow[t]{4}{*}{$\mathrm{X}$} & & & & & 0.439 & 0.982 & 0.691 & 7.576 & 12.402 & 0.007 & 0.007 & 16.680 \\
\hline & \multirow[t]{3}{*}{$\mathrm{X}$} & & & & 0.797 & 0.987 & 0.308 & 6.167 & 18.817 & 0.006 & 0.027 & 23.493 \\
\hline & & $X$ & & & 0.893 & 0.972 & 0.125 & 6.573 & 19.924 & 0.007 & 0.008 & 15.729 \\
\hline & & $\mathrm{X}$ & & & 0.576 & 0.906 & 0.207 & 5.043 & 1.495 & 0.003 & 0.005 & 23.397 \\
\hline $\mathrm{X}$ & \multicolumn{2}{|c|}{$\mathrm{x}$} & & & 0.292 & 0.989 & 0.339 & 4.416 & 7.067 & 0.035 & 0.041 & 22.863 \\
\hline$X$ & & $\mathrm{X}$ & & & 0.335 & 0.987 & 0.961 & 5.784 & 4.064 & 0.044 & 0.047 & 20.212 \\
\hline & $X 2$ & $X$ & & & 0.947 & 0.992 & 0.852 & 7.443 & 5.886 & 0.060 & 0.072 & 21.766 \\
\hline & & $\mathrm{X} X$ & & & 0.746 & 0.975 & 0.328 & 4.924 & 6.335 & 0.044 & 0.057 & 20.140 \\
\hline & & & $\mathrm{X}$ & & 0.606 & 0.123 & 0.058 & 4.498 & 0.533 & 0.012 & 0.104 & 16.897 \\
\hline & & & X & & 0.914 & 0.986 & 0.143 & 5.292 & 0.467 & 0.013 & 0.057 & 15.316 \\
\hline & & & & $\mathrm{X}$ & 0.969 & 0.989 & 0.905 & 4.800 & 0.357 & 0.011 & 0.049 & 13.977 \\
\hline & & & & X & X 0.970 & 0.993 & 0.711 & 4.406 & 0.304 & 0.010 & 0.056 & 23.070 \\
\hline & & & X X & & 0.813 & 0.980 & 0.966 & 9.941 & 5.758 & 0.418 & 0.132 & 6.060 \\
\hline & & & $\mathrm{X}$ & X & X 0.990 & 0.998 & 0.543 & 10.458 & 8.054 & 0.286 & 0.084 & 5.796 \\
\hline & & & & $x$ & 0.957 & 0.931 & 0.513 & 10.143 & 10.479 & 0.265 & 0.056 & 4.475 \\
\hline & & & & X X & 0.998 & 0.941 & 0.909 & 7.798 & 6.570 & 0.386 & 0.101 & 4.204 \\
\hline & $X$ & & $X$ & & 0.623 & 0.993 & 0.497 & 7.027 & 9.149 & 0.273 & 0.208 & 21.748 \\
\hline & & $X$ & $X$ & & 0.699 & 0.990 & 0.870 & 3.771 & 0.940 & 0.197 & 0.130 & 13.359 \\
\hline & & $\mathrm{X}$ & $\mathrm{X}$ & & 0.773 & 0.995 & 0.943 & 4.130 & 0.825 & 0.254 & 0.139 & 8.254 \\
\hline \multirow[t]{3}{*}{$\mathrm{X}$} & & & $X$ & & 0.981 & 0.888 & 0.851 & 4.374 & 0.847 & 0.253 & 0.178 & 13.147 \\
\hline & & X & X & & 0.929 & 0.707 & 0.819 & 6.516 & 15.671 & 0.203 & 0.165 & 15.254 \\
\hline & & X & X & & 0.845 & 0.848 & 0.843 & 5.497 & 15.647 & 0.183 & 0.160 & 14.334 \\
\hline \multirow[t]{3}{*}{$\mathrm{X}$} & & & & $X$ & 0.880 & 0.984 & 0.619 & 4.538 & 9.495 & 0.250 & 0.173 & 13.718 \\
\hline & $X$ & & & $X$ & 0.754 & 0.985 & 0.347 & 15.695 & 17.729 & 0.189 & 0.192 & 26.972 \\
\hline & & $X$ & & $X$ & 0.938 & 0.344 & 0.771 & 7.616 & 14.901 & 0.169 & 0.127 & 15.253 \\
\hline \multirow[t]{3}{*}{ X } & & & & X & 0.808 & 0.996 & 0.226 & 5.605 & 13.350 & 0.195 & 0.194 & 17.487 \\
\hline & $X$ & & & & 0.859 & 0.997 & 0.487 & 8.947 & 15.324 & 0.210 & 0.193 & 23.706 \\
\hline & & $X$ & & X & 0.792 & 0.628 & 0.850 & 7.746 & 8.431 & 0.172 & 0.151 & 17.617 \\
\hline \multirow[t]{4}{*}{ X } & & & $X$ & & 0.613 & 0.976 & 0.922 & 5.342 & 7.884 & 0.180 & 0.140 & 12.710 \\
\hline & $X$ & & X & & 0.964 & 0.918 & 0.533 & 6.337 & 10.451 & 0.096 & 0.061 & 10.632 \\
\hline & & X & & $X$ & 0.974 & 0.990 & 0.907 & 5.689 & 4.026 & 0.109 & 0.078 & 9.978 \\
\hline & & $\mathrm{X}$ & & X & 0.992 & 0.993 & 0.883 & 5.518 & 3.455 & 0.091 & 0.092 & 10.789 \\
\hline
\end{tabular}

